\title{
Nitroxide Bound $\beta$-Cyclodextrin: Is There an Inclusion Complex?
}

David Bardelang, ${ }^{\mathrm{a}}$ Antal Rockenbauer, ${ }^{\mathrm{b},{ }^{*}}$ Laszlo Jicsinszky, ${ }^{\mathrm{c}}$ Jean-Pierre Finet, ${ }^{\mathrm{a},{ }^{*}}$ Hakim Karoui, ${ }^{a}$ Sandrine Lambert, ${ }^{a}$ Sylvain R. A. Marque, ${ }^{a}$ and Paul Tordo ${ }^{a}$

${ }^{a}$ UMR 6517 CNRS et Aix-Marseille Université, Avenue Escadrille Normandie-Niemen, Marseille 13397, France

${ }^{\mathrm{b}}$ Chemical Research Center, Institute of Structural Chemistry, H-125 Budapest, PO Box 17

Hungary

${ }^{c}$ Cyclolab Ltd, PO Box 435, H-1525 Budapest, Hungary 


\section{Figure 1}
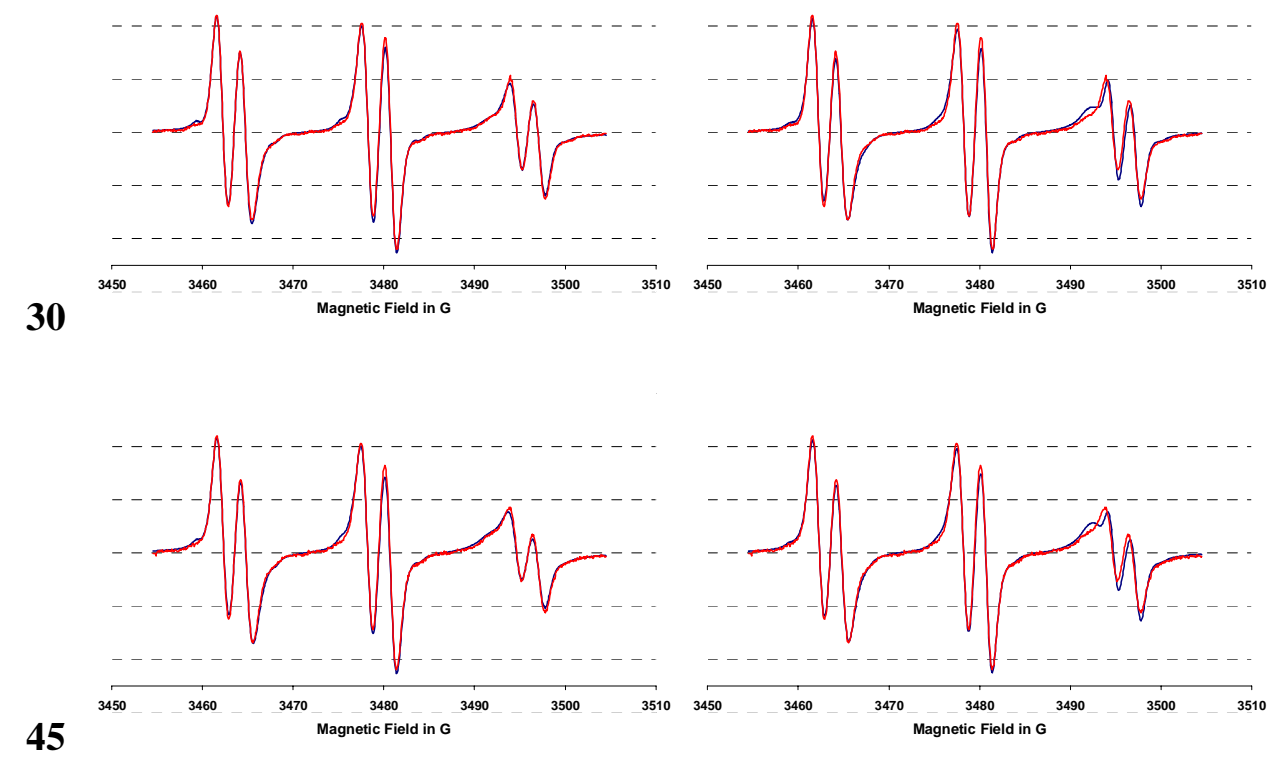

60
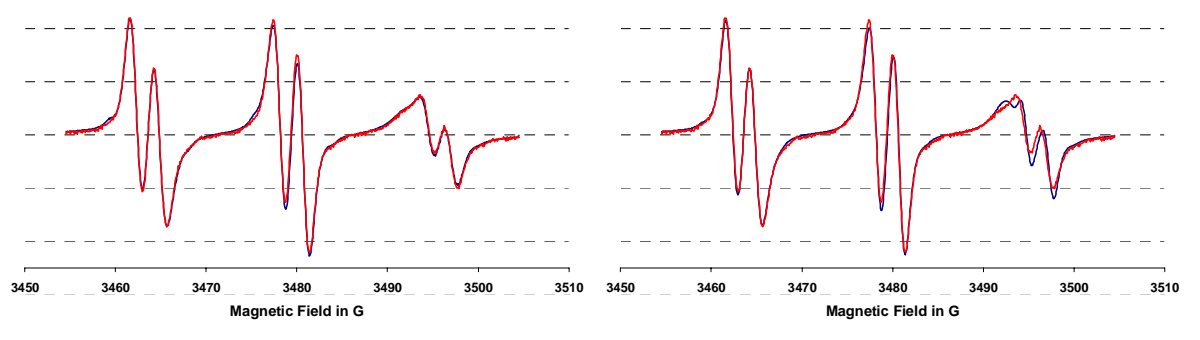

75
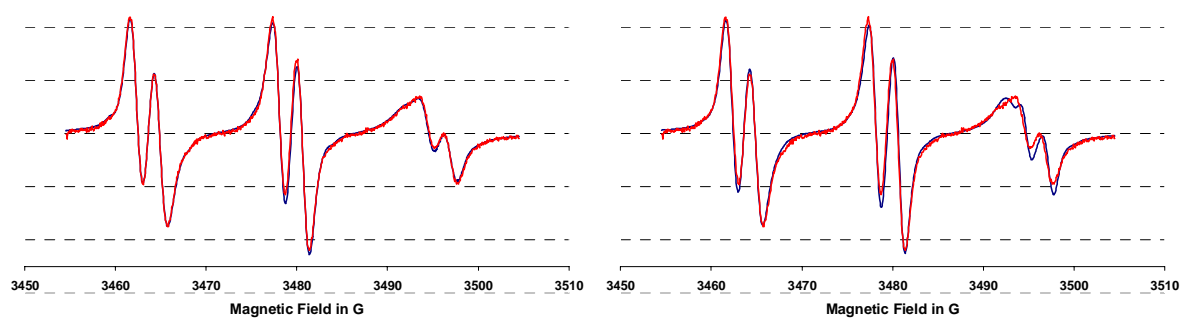

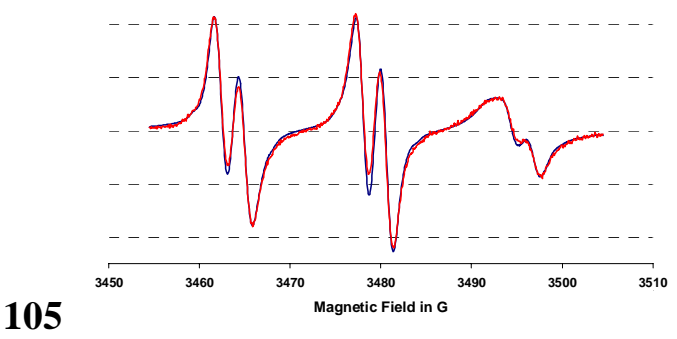

three species $(1: 0,1: 1,1: 2)$

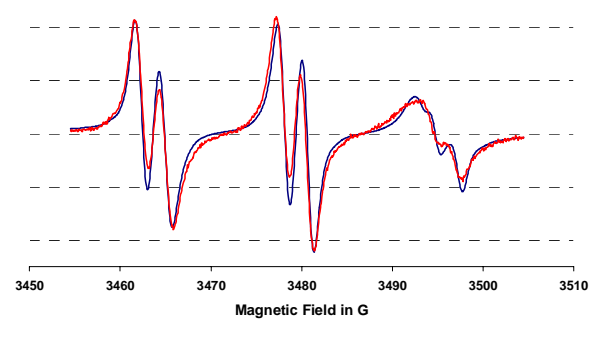

two species $(1: 0,1: 1)$

2D-simulations comparing the three and two species models, red curves: experimental, blue curves: calculated, $\mathrm{CD}$ concentrations are given in mMol units 